\title{
Absorbed Dose Measurements Using TLDS in Biological Samples from Beta Radiation
}

\author{
José Eduardo Manzoli ${ }^{1,2 *}$, Valdir de Souza Carvalho ${ }^{1}$ and Eliomar Jacinto Gomes de \\ Cerqueira ${ }^{1}$ \\ ${ }^{1}$ IPEN - Instituto de Pesquisas Energéticas e Nucleares; Av Lineu Prestes, 2242; Cidade Universitária; 05508-000; \\ São Paulo - SP - Brasil. ${ }^{2}$ Universidade São Judas Tadeu - USJT; R. Taquari, 546; Mooca; jmanzoli@ipen.br; \\ São Paulo - SP - Brasil
}

\begin{abstract}
Irradiation of samples in peculiar experimental apparatus, subject to radiation spread, requires a special evaluation of absorbed dose implanted to the sample. Indirect calibration of the irradiation source, obtained in a different apparatus, and the spread, usually of very difficult theoretical evaluation, can cause very serious measurement errors, sometimes reaching 50\%. In this work, the procedure for dose evaluation in an apparatus for beta irradiation of samples, usually biological ones, is presented, making use of calibration curves, obtained by irradiation in advance of thermoluminescent detectors in air, and so irradiating them in the same position of the sample. An application in blood sample irradiation is also presented.
\end{abstract}

Key words: Beta irradiation, beta dosimetry, thermoluminescence, biological irradiation

\section{INTRODUCTION}

Beta irradiation of biological samples has occurred in many studies, mainly for therapeutic purposes. To be subject to beta radiation in laboratory controlled experiments, biological samples, usually in liquid form, require a vessel in a peculiar experimental apparatus. This apparatus has walls in which beta radiation spread happens, affecting the desired absorbed dose in the sample and, in many situations, it is not possible to insert an instrument of direct radiation measurement at the same sample position.

Beta radiation sources have their activity informed by the manufacturer. Time integration of the dose radiation rate emitted by the source, supposedly punctual and occurring in free air, is sometimes used to calculate the absorbed dose by the sample.
This procedure can get measurement errors which could achieve $25 \%$, as will be shown, due to spreading effects in the walls of irradiation apparatus.

Thermoluminescent dosimeters (TLDs) of $\mathrm{CaSO}_{4}$ :Dy were irradiated poised on air in a radiation field generated by a beta source in order to correctly evaluate the amount of energy imparted by the beta radiation to a sample, considering the effects of an apparatus. The energy is measured in a material mass unit, in units of gray (Gy), for the quantity Absorbed Dose (D). In such a situation (air), calibration curves are correctly obtained because there is no spread. After appropriate thermal treatment, TLDs are then positioned on the biological sample apparatus and irradiated.

\footnotetext{
* Author for correspondence
} 
The absorbed dose of TLD, when obtained by the calibration curve, gives the amount of energy imparted to the sample, corrected by the ratio factor between $\mathrm{CaSO}_{4}$ :Dy and biological tissue stopping powers.

Absorbed dose evaluated by the procedure in this work shows substantial difference when compared with dose evaluation procedure supposing the irradiation from punctual sources and sample "free in the air", demonstrating that the latter is a non appropriate procedure.

\section{MATERIALS AND METHODS}

Twenty TLDs from the same sensibility batch (Manzoli \& Campos, 2003) were submitted to beta radiation in a standard apparatus for irradiation free in the air, as can be seen in (Fig. 1).

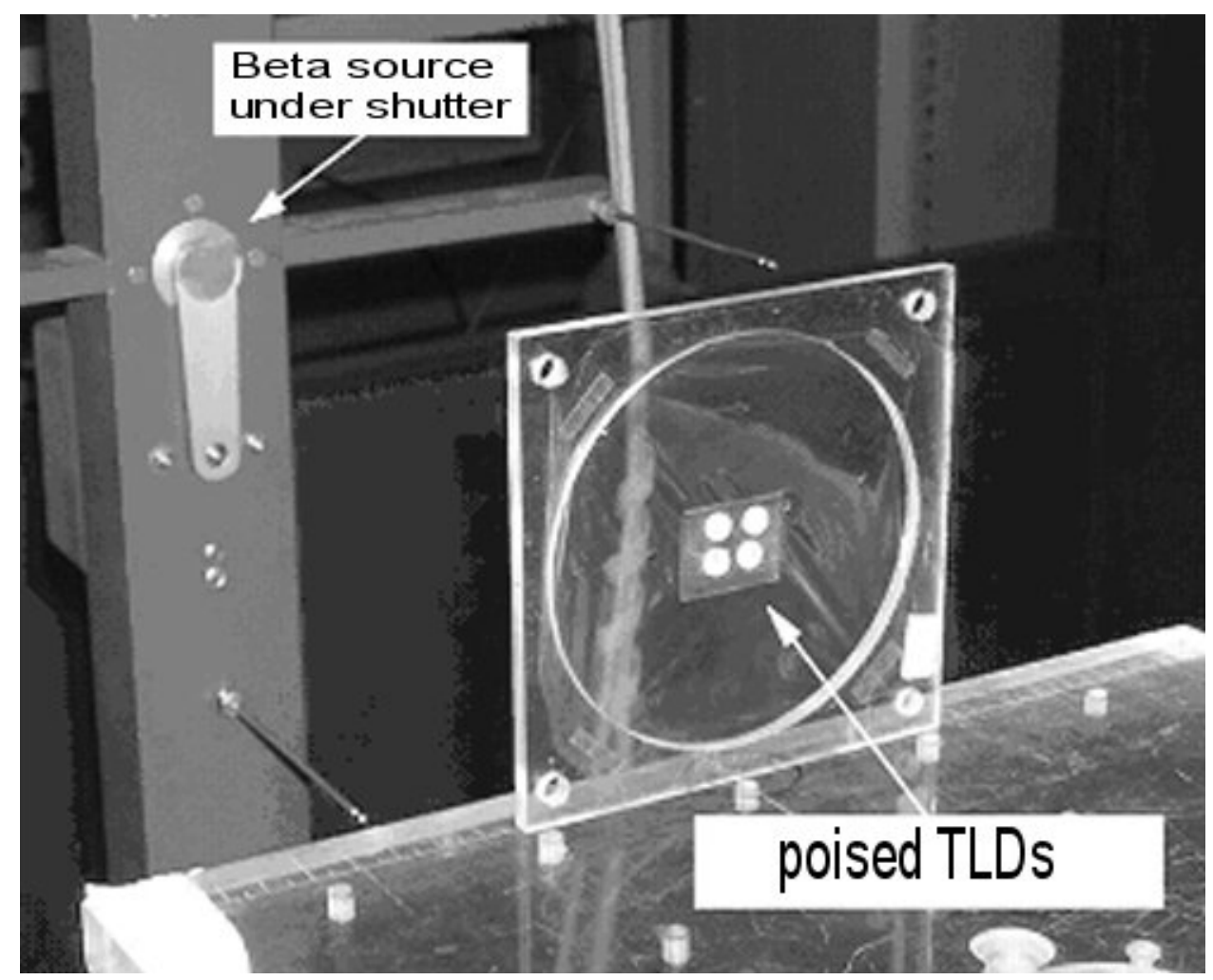

Figure 1 - Apparatus for beta irradiation of TLDs on air. TLDs are poised by a PVC film.

Beta source is a ${ }^{90} \mathrm{Sr} /{ }^{90} \mathrm{Y}$, beta emitter of maximum energy 0.546 and $2.27 \mathrm{MeV}$. Its activity was $1850 \mathrm{MBq}$ in 02/04/1981 and, by radioactive decay calculation, the absorbed dose rate in 04/26/2004 was $294 \mu \mathrm{Gy} / \mathrm{s}$, in standard position of $11 \mathrm{~cm}$ from the source.

TLDs are composites in disc form of $1 \mathrm{~mm}$ thick and $6 \mathrm{~mm}$ in diameter. The active material for thermoluminescence is $\mathrm{CaSO}_{4}$ :Dy crystals inside a polytetrafluorethilene (PTFE) matrix. Their dosimetric characteristics are recognized (Campos, 1983; Campos \& Lima, 1986) and they are sensitive to beta radiation too (Daltro et al., 1999; Campos \& Rosa, 1988; Campos \& Rosa, 1988b;
Campos \& Lima, 1987; Campos \& Lima, 1987b; Campos et al., 1986).

Thermoluminescent response of detectors, called "readings", were made in TL reader Harshaw model 2000.

Calibration curve determination was made by TLDs which were irradiated by different doses, between 1.0 and $8.0 \mathrm{~Gy}$, at the same standard position. These doses are achieved changing the irradiation exposure time. The range was chosen to fit a biological sample study. The dose conventional true values are calculated by a mathematical function proportional to the inverse of square distance from the source, whose activity 
has traceability. Radioactivity decay was taken into account.

The same TLDs were thermally treated and placed into the biological sample irradiation apparatus of
(Fig. 2). The position of TLD was identical to the sample, allowing the correct radiation evaluation because the spread effects were the same and included into the energy imparted to the TLD.

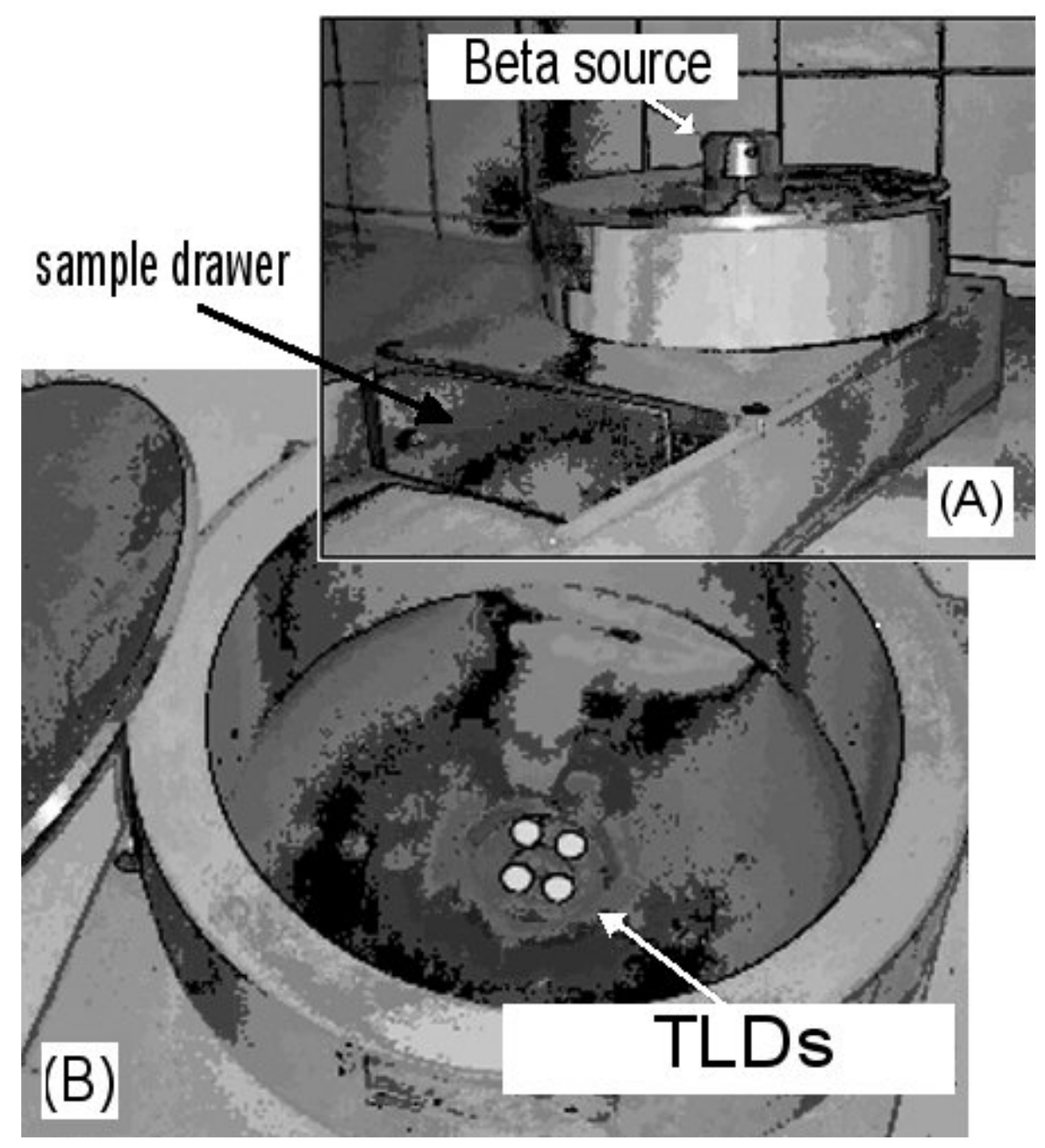

Figure 2 - Experimental apparatus for beta irradiation of biological samples. In (A), a view of closed container and the beta source on top of it. In (B), the lid is removed, allowing the view of the TLDs placed at the sample irradiation position. Side, back and top walls are aluminium made.

\section{RESULTS AND DISCUSSION}

The calibration curve of (Fig. 3) presents four points. Each one is a mean value of five TLDs irradiated free in the air. It relates conventional true values of beta radiation absorbed doses (in Gy) with electrical charge from the TL reader response (in $\mu \mathrm{C}$ ).

The calibration factor is $(0.832 \pm 0.017) \mathrm{Gy} / \mu \mathrm{C}$.

The source to sample distance, in the apparatus of (Fig. 2), is $43 \mathrm{~mm}$. In such a distance, free in the air, an irradiation of 30 minutes would be $3.46 \mathrm{~Gy}$, by the source activity and the inverse square distance consideration. By the TLD direct TL reading and use of calibration curve of (Fig. 3), the implanted energy in a $\mathrm{CaSO}_{4}$ :Dy is $4.28 \mathrm{~Gy}$. So, the dose in sulphate could be underestimated by almost $25 \%$, if scattering errors are not included.

Besides the use of the explained procedure, the absorbed dose for biological materials must be corrected, which are, of course, different from 
$\mathrm{CaSO}_{4}$ :Dy in their capacity to absorb radiation, numbers of materials. mainly due to the differences of effective atomic

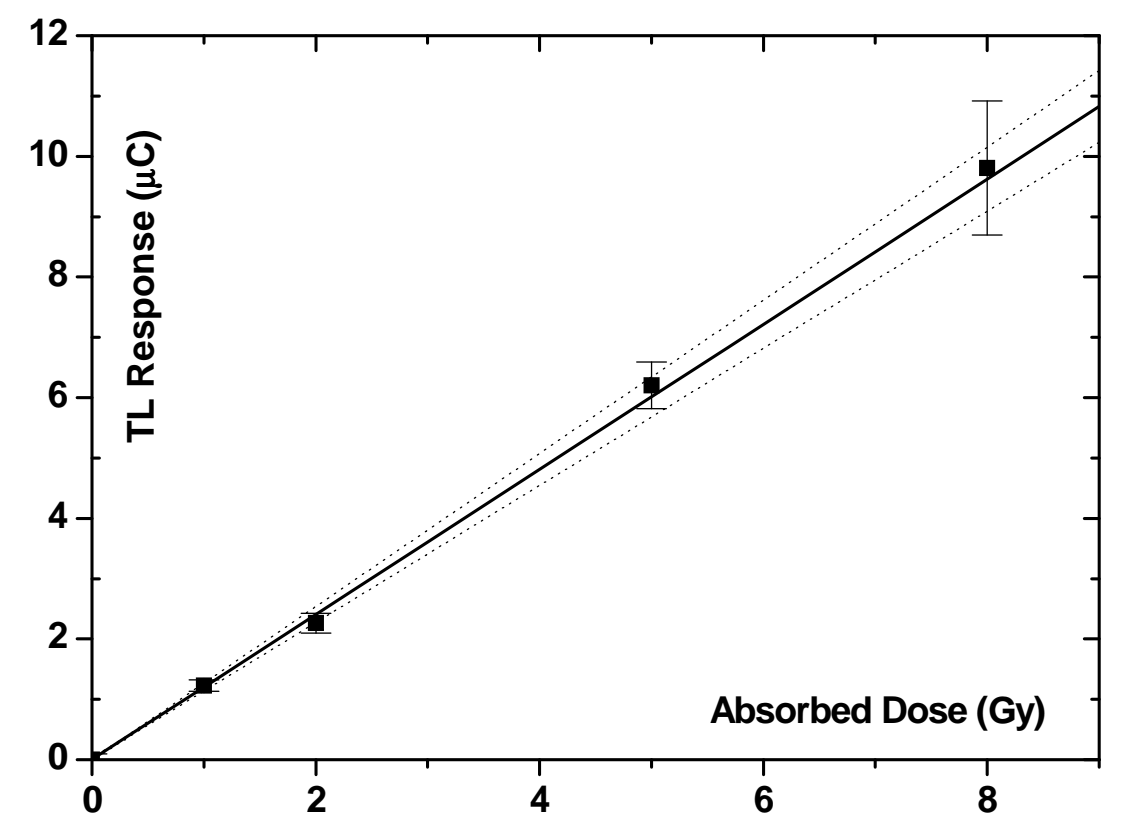

Figure 3 - Calibration curve with 95\% confidence level interval (pointed curves) for beta irradiation "free in air". Error bars are combined standard measurement uncertainties, where abcissa uncertainty was transferred to the ordinate (Vuolo, 1992).

For a blood irradiation, as an example, the correction factor, $f_{\text {corr }}$, which must be applied in the absorbed dose value, obtained by the calibration curve, is:

$$
f_{\text {corr }}=\frac{C D}{C E}=\frac{S_{\text {blood }}}{S_{\text {sulphate }}}
$$

where:

CD is how much sulphate is denser than blood.

CE is how much sulphate absorbs more energy than blood

$\mathrm{S}$ is the stopping power, defined below.

When the beta particle penetrates in calcium sulphate, it releases beta particle to the material CE times more energy than if it penetrates in blood, in a length unit. A volume of sulphate has CD more mass than the same volume of blood and, so, in a unit mass, the sulphate absorbs $\left(f_{\text {corr }}\right)^{-}$ ${ }^{1}$ times the energy that blood would absorb.
Disprosium in calcium sulphate is a doping in very small fraction (p.p.m.). Then it could be disregarded in calculations.

The ratio CD/CE is expressed by the $S$ ratio of each material, given by:

$S=\frac{1}{\rho}\left(\frac{d E}{d x}\right)=2 \pi r_{o}^{2} N_{e} \frac{\mu_{o}}{\beta^{2}}\left[\ln \left(\frac{E^{2}\left(E+2 \mu_{o}\right)}{2 \mu_{o} l^{2}}\right)+\right.$

$\left.\frac{E^{2} / 8-\left(2 E+\mu_{o}\right) \mu_{o} \ln 2}{\left(E+\mu_{o}\right)^{2}}+1-\beta^{2}-\delta\right]$

where:

$E$ is the beta particle energy (here taken as $1 \mathrm{MeV}$, average energy of beta emissions)

$\rho$ is the mass density of material

$r_{0}$ is the classic electronic ratio

$\mathrm{N}_{\mathrm{e}}$ is the electronic density

$\mu_{\circ}$ is the rest electron mass

$\beta$ is the ratio between particle and light velocities.

$\mathrm{I}$ is the mean excitation energy of material atoms. 
$\delta$ is the density correction, meaningful above $1 \mathrm{MeV}$.

The quantity values in (Eq. 2), for many materials, are found in books, example in (Johns \& Cunningham, 1983). For blood, it was assumed $\rho$, $\mathrm{N}_{e}$ and $\mathrm{I}$ as averages of values from water and muscle, mainly because these values are very close (the difference less than $4 \%$ for the parameter $\rho$ and less than $1 \%$ for the others). To $\mathrm{CaSO}_{4}$, it was assumed the mean excitation energy as $167 \mathrm{eV}$, obtained by the linear regression shown in (Fig. 4), because a rigorous calculation would be non practical for this work and, even such an excitation energy changing in the interval $[100,200] \mathrm{eV}$, there would not be a shifting in $\mathrm{f}_{\text {corr }}$ larger than $8 \%$.

The energy $\mathrm{E}$ was assumed as $1 \mathrm{MeV}$, which is the mean value of emission spectrum of any ${ }^{90} \mathrm{Sr} /{ }^{90} \mathrm{Y}$ source. This value has an influence as small as 5\% in $\mathrm{S}$, when $\mathrm{E}$ changes in interval $[0.5 ; 3] \mathrm{MeV}$.
The obtained values of stopping powers are: $2.76 \times 10^{-14} \mathrm{~J} . \mathrm{m}^{2} / \mathrm{kg}$ for $\mathrm{CaSO}_{4}$ and $3.33 \times 10^{-14}$ $\mathrm{J} . \mathrm{m}^{2} / \mathrm{kg}$ for blood, relative uncertainty of $15 \%$. The correction factor for the absorbed dose in a blood sample, when using TLDs of $\mathrm{CaSO}_{4}: \mathrm{Dy}$, is (1.21 $\pm 0.25)_{95 \%}$ (Eq. 1), which means that the dose will be $21 \%$ higher in blood, relative to the calcium sulphate. Thirty minutes of irradiation inside the apparatus will give:

\subsection{Gy (sulphate) x $1.21\left(f_{\text {corr }}\right)=5.18 \mathrm{~Gy}$ of absorbed dose for a blood sample.}

Therefore, an approximation of irradiation "free in air" (dose would be 3.46 Gy) can not merely be used for sample irradiation inside apparatus with spread walls.

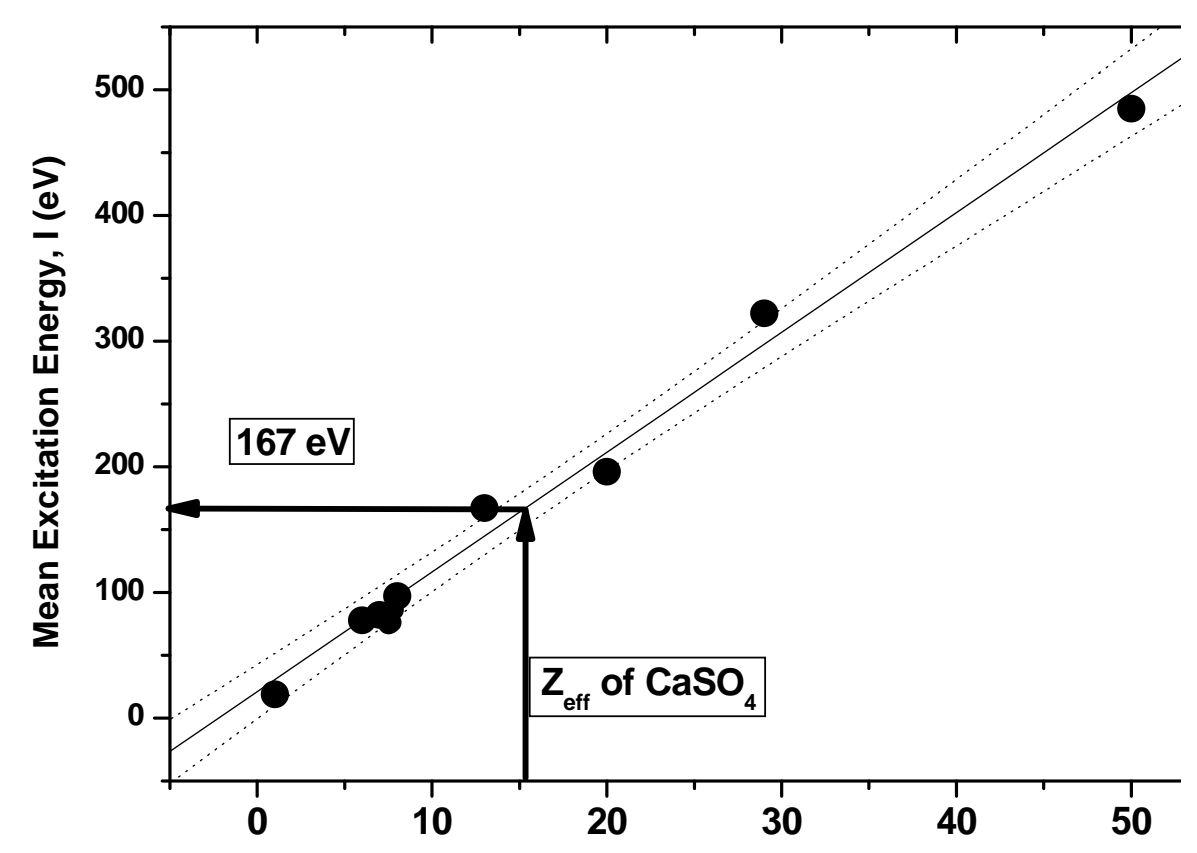

Figure 4 - Mean excitation energy values as function of atomic numbers (or effective atomic numbers) for many chemical elements and compounds (Johns \& Cunningham, 1983). Due to this linear behavior it was estimated such an energy of $\mathrm{CaSO}_{4}$, whose $\mathrm{Z}_{\mathrm{eff}}$ is 15.3 u.m.a., as $167 \mathrm{eV}$. 95\% confidence level of the linear regression are in dotted lines.

The use of calibrated TLDs, small sensors which are placed in the sample position, is an alternative 
for an indirect measurement in peculiar apparatus. Stopping powers of the sample and of TLD material should be taken into account.

\section{ACKNOWLEDGMENTS}

The authors are grateful to the technical staff of LDT-IPEN (Vicente, Osvaldo, Fátima and Salomão).

\section{RESUMO}

A irradiação de amostras em arranjos experimentais peculiares sujeitos a espalhamento necessita de uma determinação própria da dose absorvida que a amostra irá receber. A calibração indireta da fonte de irradiação, que ocorre em arranjo diferente, e o espalhamento, geralmente de difícil estimativa teórica, podem causar erros de medição muito elevados, não raro atingindo $50 \%$. Neste trabalho é apresentado o procedimento para determinação da dose absorvida em um arranjo para irradiação beta de amostras, normalmente biológicas, utilizando curvas de calibração obtidas pela irradiação de dosímetros termoluminescentes no ar, e os irradiando na mesma posição das amostras. É apresentado um exemplo de aplicação para amostra irradiada de sangue.

\section{REFERENCES}

Campos, L. L. (1983), Preparation of CaSO4:Dy TL single crystals. J. Lum., 28 : (4), 481-483.

Campos, L. L. and Lima, M. F. (1986), Dosimetric Properties of $\mathrm{CaSO}_{4}$ :Dy teflon pellets produced at IPEN. Rad. Prot. Dos., 14, 333-335.

Campos, L. L. and Lima, M. F. (1987), Pastilhas Dosimétricas de CaSO4:Dy + Teflon para Detecção da Radiação Beta, X e Gama. Publ Ipen., 120, 1-10.

Campos, L. L. and Lima, M. F. (1987b), Thermoluminescent CaSO4:Dy + Teflon Pellets for Beta Radiation Detaction. Rad. Prot. Dos., 18, 95-97.

Campos, L. L. and Rosa, L. A. R. (1988), Caesium - 137 Beta / Gamma Discriminating Thermoluminescent Dosimeter. Rad. Prot. Dos., 25, 95-97.

Campos, L. L. and Rosa, L. A. R. (1988b), Determinacao Simultânea das Doses Absorvidas Devido `as Radiações Beta e Gama com CaSO4 Produzido no IPEN. Publ Ipen., 143, 1-10.

Campos, L. L.; Caldas, L. V. and Mascarenhas, S. (1986), Investigation of Teflon Electrets Detectors for Beta Dosimetry. Nuclear Instruments \& Methods in Physics Research, 245, 210 - 212.

Daltro, T. F. L.; Perez, H. E. B. and Campos, L. L. (1999), Thermoluminescence Dosemeter for Equivalent Dose Assessment in Beta and Gamma Field. Rad. Prot. Dos., 85 : (1-4), 145-148.

Johns, H. E. and Cunningham, J. R. (1983), The Physics of Radiology. 4. ed. Springfield: Charles C. Thomas. pp. 193-216.

Manzoli, J. E. and Campos, V. P. (2003), Selecionamento de Detectores de Radiação Segundo sua Sensibilidade e Viabilidade para Dosimetria Termoluminescente. In: Metrologia - 2003: Metrologia para a Vida, Sociedade Brasileira de Metrologia (SBM), Recife. Anais... Recife, Pernambuco, Brasil.

Vuolo, J. H. (1992), Fundamentos da Teoria de Erros. 2. ed. São Paulo: Edgar Blücher. pp. 125.

Received: July 29, 2005; Revised: September 05, 2005; Accepted: November 22, 2005. 